\title{
Ser viejo en Madrid. El Hospital de Incurables de Jesús Nazareno y otros centros de asistencia a los ancianos ${ }^{1}$
}

\author{
Florentina Vidal Galache
}

\begin{abstract}
Edad caduca, vana y transitoria, que con la furia que en el paso llevas, envejeciendo vas las cosas nuevas, sepultando en olvido la memoria...
\end{abstract}

Catalina de la Cerda y Mendoza (1616): Soneto al doctor Cristóbal Pérez de Herrera

Dentro de los amplios límites del mundo de la pobreza hay sectores que siempre preocuparon de manera preferente. En España, la asistencia a los expósitos y a la infancia desvalida en general ha estado siempre presente en el pensamiento de gobernantes y teóricos; desde el siglo XVI, esta inquietud se materializó en la creación de instituciones de exclusiva atención a los niños abandonados ${ }^{2}$.

No conocemos bibliografía actual sobre este tema.

Desde 1567, la Inclusa de Madrid se ocupó de la crianza de niños abandonados hasta los siete años; el Colegio de Niños Desamparados (1596) los acogía a partir de esa edad hasta completar su formación. Para las niñas se fundó en el siglo XVII otra institución similar: el Colegio de Nuestra Señora de la Paz (1669). Cf. Vidal GaLACHE, B. y F., "El Colegio de Nuestra Señora de la Paz para niñas expuestas de Madrid, a mediados del siglo XVIIIm, Anales del Instituto de Estudios Madrileños 1992, págs. 191-208. Idem, Bordes, bastardos, ilegítimos y espúreos. Madrid, Ed. El Museo Universal, en prensa. 
Pero había otro colectivo, tanto o más necesitado de ayuda que los niños expuestos, al cual no se prestaba una atención específica e individualizada: los ancianos enfermos o sin recursos que durante siglos tuvieron acogida en centros benéficos, llamados en general "hospitales", donde se atendía por igual a los enfermos, peregrinos, huérfanos, viudas $y$ todo un conjunto de personas marginadas a las que daban comida $y$ techo, por unos días o por largas temporadas.

Estos establecimientos, verdaderos asilos-enfermerías, sirvieron también de última morada a viejos sirvientes o esclavos de familias benefactoras de la institución, y en ellos se administraba el dinero legado por los amos o señores en concepto de pensión. Fueron el refugio de los últimos años de muchos empleados de las propias instituciones que solicitaban este servicio como una recompensa a sus años de trabajo, como que sucedió repetidas veces con administradores o capellanes del Hospital General de Madrid ${ }^{3}$.

En 1460 , el secretario y tesorero de Juan II y Enrique IV convirtió en asilo unas casas de su propiedad, en la calle y plazuela de Santa Catalina de Madrid; "para doce pobres honrados á quienes la demasiada edad quitó la fuerza para ganar el sustento" y que fueron conocidos como "los Donados". El apelativo les venía de su vestimenta, una saya de paño pardo, con caperuza, similar a la de los monjes donados; con el tiempo la calle donde estaba situado el asilo tomó el nombre de la institución. Dice Mesonero ${ }^{4}$ que en esas casas se llegaron a albergar personajes de alcurnia, como el propio Carlos V.

Este pequeño albergue, denominado también «hospital», existió hasta mediados del $x \mid X$, aunque las condiciones de vida (que en principio fueron similares a las de una comunidad religiosa) y la regla del fundador habian cambiado por esas fechas.

Salvo este pequeño número de privilegiados, los ancianos desamparados de Madrid, sin domicilio fijo, iban a parar al Hospicio del Ave María y San Fernando (1668), que en principio se fundó para dar cobijo a pobres sin hogar. En otros puntos de España existieron casas de recogida de mendigos, con el apelativo de Casas de Misericordia ${ }^{5}$, que entre sus

${ }^{3}$ En las actas de la Junta Municipal de Beneficencia de los años 1822-1823 aparecen numerosas peticiones en este sentido, que siempre eran atendidas. Cf. Libro de Actas de la Junta Municipal de Beneficencia, 1822-1823. Archivo de la Villa, Sección Secretaría, Libro 186.

4 Mesonero Romanos, R., El antiguo Madrid. Madrid, 1990, pág. 98, 1. a ed. 1861.

5 Teóricos de la beneficencia del siglo xvı, como Pérez de Herrera, Giginta y otros, promovieron la creación de establecimientos de recogida de mendigos, tanto para su control, distinguiendo al verdadero pobre del fingido, como para proporcionar a los primeros domicilio y 
habituales acogian a los ancianos sin recursos. Fundado por el protomédico de galeras de Felipe II Cristóbal Pérez de Herrera ( $† 1620)$ existió por breve tiempo en la capital uno de esos establecimientos, el Albergue Real (1596), en el mismo solar donde luego se levantaría el Hospital General ${ }^{6}$. En el albergue, a diferencia de los hospicios creados por los hospitalarios de San Juan de Dios, nunca se mezclaron individuos sanos con enfermos porque su finalidad era la de servir de "parroquias y dormitorios»; los acogidos debian oír misa cada mañana, aprender doctrina cristiana "para hacerse hombres de bien y virtuosos" y vivir de las limosnas recolectadas ${ }^{\text {? }}$.

A partir del último tercio del siglo XVIII, el Estado intentó canalizar los bienes destinados tradicionalmente por la Iglesia y los particulares para la atención a los necesitados, institucionalizando la caridad. La consideración social del pobre ya estaba muy lejos de la óptica de la caridad cristiana que estimaba la ayuda a los menesterosos como un medio de salvación y los mendigos inútiles eran vistos como un estorbo, e incluso un peligro para la seguridad de la Corona. Todos los pobres no válidos para el trabajo, junto con pequeños delincuentes, prostitutas, y niños sin hogar mayores de siete años, van a ser encerrados en el Hospicio que se convertiría en una verdadera cárcel.

Los planes de beneficencia arbitrados por los monarcas ilustrados, materializados por Carlos III, que daban asistencia y hospitalidad domiciliaria a los pobres honrados (jornaleros en paro, sus viudas y huérfanos) que carecieran de trabajo o que se vieran en graves dificultades económicas, excluían de sus prestaciones a los enfermos crónicos, como lo eran la mayoría de los ancianos, y a todos aquellos que carecieran de domicilio. A los viejos, como a los demás necesitados, se les proporcionaba socorro en dinero si se estimaba que su petición tenía fundamento, sin que la circunstancia de la edad estuviera especialmente contempla$\mathrm{da}^{8}$.

sustento. Vid. de Pérez de Herrera, Cristóbal, Discurso del amparo de los legítimos pobres y reducción de los fingidos... I. Madrid, Luis Sánchez, 1598 y GiGINTA, M. de, Exhortación a la comprensión de los pobres. Barcelona 1583.

${ }^{6}$ Situado al final de la calle de Atocha, en una parte de la hacienda cedida para este fin por el cardenal arzobispo don Pascual de Quiroga. Cf. Constituciones y ordenanzas para el gobierno de los Reales Hospitales General y Pasión de Madrid. Madrid, I Real, 1789, fol. 3.

7 Cavillac, M., Introducción a la obra de Pérez de Herrera, Cristóbal, Amparo de los pobres. Madrid, Espasa Calpe, 1975, pág. CLI, $1 .^{a}$ ed. 1594.

${ }^{8}$ Cevallos, Pedro de, Reglamento formado por la Real y Suprema Junta General de Caridad para el gobierno de la hospitalidad domiciliaria... Sacedón, I. Real, 1816. 
Pese a los intentos del Estado para centralizar la asistencia a los necesitados, en Madrid continuaron con su labor benéfica algunas instituciones privadas que ejercian la caridad indiscriminada, como la Junta Parroquial de San Sebastián ${ }^{9}$ y la Hermandad del Refugio ${ }^{10}$, que entre sus múltiples prestaciones incluían la de asistir a los pobres en sus domicilios, con dinero, médico y medicinas. Naturalmente muchos de sus protegidos serían ancianos necesitados, pero tampoco se cuidaba de forma especial la asistencia a este colectivo.

Los trabajadores que pertenecían a gremios y cofradías profesionales tuvieron ayudas en situaciones de enfermedad, muerte o viudedad, hasta la extinción definitiva de tales asociaciones en 1836; las prestaciones tenían una duración limitada y era condición indispensable la cotización del beneficiario. Pero gran parte de la población laboral no cualificada, como los jornaleros, no pertenecían a ningún gremio o asociación y no podía esperar ningún socorro fijo cuando la enfermedad o la vejez les impedia trabajar; no les quedaba más recurso que los hospitales públicos, rechazados de forma unánime por los pobres, o el hospicio, donde permanecian hasta la muerte.

Con el paso de los años el conjunto de la sociedad pasaría a considerar el problema de la asistencia a los pobres como un deber social de los poderes públicos. Por otra parte, los avances de la medicina dieron lugar a una especialización de los hospitales, que dejaron de ser asilos permanentes de sanos y enfermos para pasar de forma gradual a convertirse en centros destinados a la curación, excluyendo muchos de ellos a los enfermos crónicos y a los viejos cuya única patología fueran los achaques propios de la edad y que necesitaban de lugares especializados, aún inexistentes.

A partir de 1834 la capital contó con otro establecimiento de recogida de mendigos, verdadera cárcel, de régimen similar al seguido en el Hospicio, donde fueron a parar muchos ancianos desvalidos: el Asilo de San Bernardino. Fue creado durante la epidemia de cólera de 1834 para apartar de la calle a los marginados. Las autoridades sabían, por experiencia, que los pobres eran un peligroso medio de propagación de enfermedades; también se temía por el terror y el desorden causado por la epidemia

\footnotetext{
9 Sobre las actividades de la Junta Parroquial de San Sebastián vid. de VIDAL GALACHE, B. y F., "Enfermar en Madrid" y “Los médicos en el Madrid el siglo xIx", en Historia 16, 172, págs. 31.36 y 176 , págs. $33-38$.

10 Callahan, W. J., La Santa y Real Hermandad del Refugio y Piedad de Madrid. 1618-1832 Madrid, C.S.I.C, - A.I.E.M. IEM, 1980.
} 
movilizaran aquellas masas incontroladas en un levantamiento popular contra la Administración. La matanza de frailes, a quienes el populacho atribuyó la contaminación de las fuentes, ocurrida a mediados de julio, precipitó la apertura del Asilo en condiciones muy precarias. San Bernardino llegó a ser el mayor depósito de pobres de Madrid ${ }^{11}$ y un indicativo de la miseria general de la capital, porque estaba muy solicitado pese a las condiciones de represión que se daban en él.

\section{UN ESTABLECIMIENTO ORIGINAL PARA LA ASISTENCIA A LAS ANCIANAS EN EL MADRID DEL SIGLOXVI}

Siguiendo el modelo de otras cofradías y hermandades religioso-benéficas del siglo XVI, en 1596 la Congregación del Amor de Dios y la Santísima Virgen de los Desamparados se dedicó al socorro de un heterogéneo colectivo de marginados que incluía a doce ancianas achacosas, denominadas "carracas" por el vulgo. También asistían a parturientas pobres, mendigos sin domicilio a los que daba albergue por las noches, y niños desamparados que generalmente habian sido encontrados vagando por las calles.

En un principio se llamó Hospital de los Desamparados y no tomó el nombre de Colegio hasta que Felipe ll destinó allí a los niños huérfanos que, por mandato suyo, estaban desde 1592 en el Colegio de Niñas de Santa Isabel. Con los años la fundación pasó a ser el Colegio de los Desamparados, a donde iban a parar los chiquillos procedentes de la Inclusa que hubiesen cumplido los siete años.

Pero la Congregación no abandonó totalmente sus otras facetas caritativas, excepto en lo referente a los mendigos callejeros. Que sepamos es éste el único antecedente en la capital de un centro benéfico con una cierta dedicación a las ancianas enfermas o impedidas. Esta labor continuó sin interrupción hasta el año 1805, fecha en la que la Junta Rectora del Colegio -integrada por miembros de la nobleza colegiada de Madrid--, solicitó al Consejo de Castilla que la sala de mujeres impedidas, y la destinada a maternidad, fueran dedicadas exclusivamente a los niños. Alegaban que el alto costo que suponía la asistencia a las ancianas y parturientas podía ser sufragado por los hospitales públicos General y Pasión ${ }^{12}$. Dos años antes se había fundado en Madrid el Hospital de Jesús

Sobre el Asilo de San Bernardino vid. VIDAL GaLACHE, F, «iQué hacemos con los pobres? El origen del Asilo de San Bernardino", en Espacio, Tiempo y Forma 1992, págs. 305-316.

12 Las parturientas eran atendidas en el Hospital General que, salvo este servicio, estaba 
Nazareno, dedicado exclusivamente a las viejas achacosas, y probablemente en su existencia se basó la decisión de cerrar la enfermería de las "carracas".

Por Real Orden de 11 de noviembre de 1805 se terminaba con las prestaciones a mujeres en el Colegio de los Desamparados, con la salvedad de las "carracas" que ya estaban en la casa, a las que se atendería hasta su fallecimiento. La guerra de la Independencia, con sus terribles secuelas de miseria, desbarató los planes de reforma, y en los Desamparados se continuó admitiendo a mujeres impedidas hasta 1817.

\section{EL HOSPITAL DE JESÚS NAZARENO DE MUJERES INCURABLES}

Esta fundación, nacida a principios del siglo xix, reunía todas las características de aquellas instituciones de caridad de los siglos XVI y XVII que en origen surgieron de la iniciativa privada y, dado su interés público, pasaron más tarde a la tutela de la Administración.

En el año 1800, la condesa viuda de Lerena, marquesa de San Andrés, solicitó el permiso real para fundar un hospital dedicado al cuidado de las mujeres ancianas, impedidas o afectadas de enfermedades consideradas incurables, como parálisis y "chochez". Conseguida la real autorización en el año 1803, aquel piadoso establecimiento se instaló en la calle de Conde Duque, esquina a la del Limón número $4^{13}$. En 1815 fue trasladado a la calle del Burro, hoy Colegiata, y en 1824 les fue cedida por el Rey el inmueble que había albergado el Colegio de Niñas de Monterrey, fundado por Felipe $V$ en la casa del conde de este título, en la calle de Amaniel número 11. En 1851 el edificio, al que Mesonero califica de precioso hospital, sufrió un terrible incendio que destruyó diecisiete casas.

Con los años, el Hospital de Jesús Nazareno sería conocido bajo el más cruel de los apelativos, un nombre que implicaba la pérdida de toda esperanza: el Hospital de Incurables.

La condesa viuda de Lerena reunió un grupo de señoras piadosas - llamadas Damas Tutoras - y con ellas se ocupó del centro, concebido

destinado a los hombres. Había también salas de maternidad en otras instituciones privadas de beneficencia, como Nuestra Señora de la Esperanza o Pecado Mortal, un centro de represión para mujeres pobres.

${ }_{13}$ Varios documentos y noticias sobre el Hospital de Incurables, 1826-1835. AV-C, 1-195-2. C, $1 \cdot 195-2$. 
realmente como un asilo de ancianas. Este planteamiento caritativo, aún bajo las directrices del más puro pensamiento ilustrado, estaba en la línea de actuación de muchas damas de alta cuna que dedicaban parte de su tiempo y su fortuna a labores filantrópicas. Un ejemplo significativo era la amplia labor de la Real Junta de Damas Nobles dependiente de la Real Sociedad Económica Matritense, a cuyo cargo estaban la Inclusa, el Colegio de la Paz y otras escuelas de formación profesional para niñas y adultos pobres ${ }^{14}$.

\section{LAS CONDICIONES PARA LA ADMISIÓN Y VIDA EN EL HOSPITAL}

En el Reglamento ${ }^{15}$ se especificaba que las ancianas aspirantes al Hospital de Jesús Nazareno debían carecer de hijos que las cuidaran y ser pobres pero "no mendigas que fueran de puerta en puerta"; en resumen, personas necesitadas pero de una cierta calidad de vida, lo que se conocía como pobres vergonzantes.

Sólo se admitía a mujeres incurables, tullidas o muy ancianas que no se pudieran valer por sí mismas. No se acogía a las de males contagiosos, calenturas, "llagas", o enfermedades que necesitaran tratamiento. Además de las ancianas, estaba prevista la admisión de niñas tullidas que no tuvieran padres ${ }^{16}$. Los hombres no tenían derecho a ser atendidos en el establecimiento tampoco las mujeres castigadas por la Santa Inquisición, aunque estuvieran absolutamente inútiles ${ }^{17}$.

El hospital debía mantenerse exclusivamente con limosnas recogidas personalmente por las Damas Tutoras, con una bolsa y de puerta en puerta, convenientemente acompañadas de un lacayo. También podían obtener fondos pidiendo a la entrada de los principales templos. Para facilitar la tarea se repartian entre todas ellas la visita a los diferentes barrios de Madrid. Todos los domingos se reunia la Junta de Tutores con su presidenta, para tomar decisiones sobre la Casa. El modelo era el de una gestión directa y personal, tanto en la forma de recaudación de fondos como en la proximidad a las ancianas asiladas y sus problemas; dos

${ }^{4}$ Ct. Demerson, Paula, Maria Francisca de Salas y Portocarrero, duquesa de Montijo, una figura de la llustración. Madrid 1975.

is Reglamentos y constituciones de la Casa Hospital de Jesús Nazareno para pobres impe. didas. Madrid, I Real, 1803.

${ }^{16}$ En el Colegio de los Desamparados también se acogió, hasta principios del siglo xix, a niñas tullidas procedentes de la Inclusa, que habian rebasado los siete años. Estas niñas permanecian de por vida en el colegio, disfrutando "plaza de inválida", a cargo de la Inclusa.

17 Reglamentos... 1803, pág. 31 
circunstancias que fueron la clave del éxito de muchas cofradias y asociaciones religioso benéficas del Siglo de Oro.

El sistema de financiación, basado exclusivamente en las limosnas, no debió ser suficiente para mantener el hospital y cuando en 1812, en plena ocupación francesa, ocurrió la terrible crisis de subsistencia, tuvo que cerrar durante tres años por absoluta falta de fondos ${ }^{18}$. A partir de 1815 el hospital reanudó su labor con ayuda de subvenciones reales, ampliando su asistencia a seis enfermas más.

En 1821 el hospital contaba como único ingreso fijo con 24.020 reales de subvención sobre arbitrios piadosos, procedentes de los derechos de puertas cedidos por Carlos IV a beneficencia, y rentas eclesiásticas (indulto cuadragesimal, bula de cruzada y otros), pero hacía un año que no se cobraban. También tenian medicinas gratuitas de la Botica Real, por valor de 1.040 reales.

Las rentas eventuales eran las limosnas recogidas por las señoras y los distintos donativos particulares. No tenian ningún capital en efectivo, pero sí ocho vales reales y algunas alhajas de poco valor: dos copones de plata y un cáliz. El gasto total de la casa era de 65.440 reales al año ${ }^{19}$.

\section{EL PERSONAL ASISTENTE}

En principio el hospital debía ser dirigido por un sacerdote, que hacia los oficios de rector, cuyas obligaciones eran las de celebrar misa todos los días en la enfermería, administrar los sacramentos a las ancianas y explicarles los fundamentos de la doctrina cristiana. Otro de sus cometidos era el rezo diario del rosario con las asiladas.

En origen estuvo prevista la fundación de una congregación de treinta religiosas de clausura - Hermanas de Jesús - que tendrían su noviciado en el mismo hospital, con la misión de cuidar a las ancianas, repartiéndose las labores domésticas y asistenciales. Sólo serían admitidas mujeres solteras, limpias, de buenos informes y conocida virtud. Como dote debían entregar a su entrada 200 ducados que se invertirían en equipo: hábito, túnicas, ropa de cama, etc. Si recibían alguna herencia o mayorazgo, la legarían íntegra a la institución. Profesarian después de un año de novi-

18 Monlau, P. F., Madrid en la mano. Madrid, Ed. Blázquez, 1983, pág. 228, 1. a ed. 1850.

19 Pacheco de Magar, M. ${ }^{a}$ Dolores, Estadística de los establecimientos de beneficencia. Madrid 16 de julio de 1821, AV-C 1-5-14. 
ciado, durante el cual recibirían enseñanzas de latín, seguramente con la intención de que ayudaran en los oficios religiosos ${ }^{20}$. La Congregación de Hermanas de Jesús no llegó a materializarse y en el año 1821 eran seis Hermanas de la Caridad, que desde principios de la centuria iniciaron su trabajo en los distintos establecimientos benéficos, las que se ocupaban de las ancianas. Había también capellán, mayordomo, demandadero, portero, médico y cirujano. Dado que el número de asiladas en estos momentos era de trece, debían estar muy bien atendidas.

En 1848, al final de la etapa estudiada, las personas asistidas eran ya ciento nueve y el personal del hospital se componía de un director, un comisario de entradas, un capellán, dos profesores de medicina que se alternaban por meses, dos practicantes, veinte Hermanas de la Caridad, un mozo de cocina, tres lavanderas, dos demandantes y el encargado de la noria.

El Hospital de Incurables pasaba por la misma escasez de recursos que el resto de los establecimientos similares de Madrid, con el agravante de no contar con ninguna renta fija. Con frecuencia la Junta de Tutoras solicitaba ayuda para arreglos o mejoras en los sucesivos domicilios, o para cubrir necesidades vitales, pero no siempre recibian la respuesta deseada. Por ejemplo en 1818 la Junta pidió al Rey "leña para las coladas", pero no se la dieron. En 1824 pedían al Ayuntamiento que les fueran concedidos cuatro maravedíes por entrada en los teatros para reparaciones del edificio de la calle de Amaniel; la respuesta fue también negativa, "por estar las entradas ya muy gravadas...", y en 1826 volvieron a pedir al mismo estamento ayuda económica para resolver una gravísima necesidad. Esta vez consiguieron la franquicia de puertas en productos de consumo que suponían alrededor de 7.000 reales al año ${ }^{21}$.

El Hospital de Incurables pasó a depender de la Junta Municipal de Beneficencia durante la segunda etapa de mandato liberal, según lo ordenado por la Ley General de Beneficencia de 1822. En la primera etapa de vigencia de esta ley (1822-1823) no se incluyó al Hospital de Incurables entre los centros públicos de beneficencia - como se hizo con el Hospital General, Inclusa, Hospicio, etc.-, quizás porque en éste se atendía a pocas ancianas y no recibia subvenciones fijas de la Corona.

A partir de 1836 el número de enfermas fue aumentando progresivamente de forma paralela a la disminución de los ingresos fijos, sobre todo

Reglamento... 1803, págs. 3 y 35.

${ }^{21}$ Varias noticias... AV-C 1-195-2. 
de limosnas, como consecuencia del cambio en la mentalidad de la sociedad con respecto a la ayuda a los necesitados, que esta época se pretendía fuera asumida por el Estado.

En 1848 los ingresos procedían en su mayor cuantía de las estancias de las enfermas de pago -50.000 reales-. Por consignaciones del Estado recibian 24.000 reales, de limosnas y legados 10.000. Rentas de inmuebles - dos tiendas - y venta de diversos efectos (ropa vieja de las fallecidas, medicinas sobrantes) sumaban 7.904 reales. En total 89.965 reales.

El gasto era de 246.628 reales. La partida mayor correspondía a las estancias de enfermas y asiladas - ciento nueve en total-; otros gastos eran el pago de salarios y la comida del personal que superaba los 62.000 reales. La reparación y conservación del edificio, muebles, ropa y el gasto de la iglesia completaban el total. El grave déficit era pagado por la Junta Municipal de Beneficencia ${ }^{22}$.

A mediados del siglo fallecian en el hospital unas cuarenta mujeres al año; este número tan alto de defunciones se justifica porque la población asistida estaba compuesta de personas mayores y enfermas terminales, que no salían del establecimiento más que muertas.

El Hospital de Incurables cumplía una función útil aunque insuficiente, dado que solamente podían atender a un número muy limitado de enfermas. Del mismo modo que los demás centros públicos de beneficencia, fue bajando su calidad de vida al tiempo que aumentaba el número de acogidas y se limitaban sus rentas, sobre todo a partir de que los liberales lo consideraron por fin centro público de beneficencia en 1836.

Los ancianos enfermos no tuvieron en Madrid un establecimiento de similares características hasta 1852, en que se fundó el Hospital de Nuestra Señora del Carmen, de la calle de Atocha, en el edificio antes ocupado por la Casa de Reclusión para Mujeres de San Nicolás de Bari.

${ }^{22}$ Madoz, Madrid, Audiencia, Provincia, Intendencia, Vicaria, Partido y Villa. Madrid, Ed. AbaCo, 1976, pág. $363,1{ }^{\text {a }}$ ed. 1848. 